\title{
UNIVERSAL CURRENT-CONVEYOR-BASED CURRENT-MODE FILTER WITH SINGLE INPUT AND FIVE OUTPUTS
}

\author{
MUHAMMAD TAHER ABUELMA'ATTI \\ and AAMIR ALAM FAROOQUI \\ Kind Fahd University of Petroleum and Minerals \\ Bos 203 Dhahran 3126 Saudi Arabia
}

\begin{abstract}
A new universal active current-mode filter with single input and five outputs is presented. The proposed filter avoids the use of external feedback in any part of the circuit and uses grounded resistors. The proposed circuit can simultaneously realize lowpass, highpass, bandpass, allpass, and notch biquadratic filter functions.
\end{abstract}

\section{INTRODUCTION}

At present, there is a growing interest in designing current-mode currentconveyor-based active filters. This is attributed to their higher signal bandwidths, greater linearity and larger dynamic range [1]. Thus, a number of circuit realizations for universal current-mode filters have been proposed [2-11]. A critical study shows that while some of the proposed circuits use grounded resistors and capacitors [2-7], other circuits use floating resistors and/or capacitors [8-11]. The majority of the proposed circuits can realize all the basic biquadratic filter functions, that is, lowpass, highpass, bandpass, allpass, and notch. However, this cannot be achieved simultaneously. Finally, most of the circuits employ external feedback in part of the circuit in order to realize the transfer functions required. This may result in instability problems, especially at high frequencies where the non-idealities of the current-conveyors cannot be ignored.

As an illustrative example, consider the most-recent circuit proposed by Chang [2]. While the circuit can simultaneously realize lowpass, highpass and bandpass functions, to obtain an allpass function it is necessary to connect the three output currents. Similarly, to obtain a notch function it is necessary to connect the highpass and the lowpass output currents. Thus the five basic filter functions cannot be realized simultaneously. While the circuit has the advantage of using grounded resistors and capacitors, it employs external feedback in part of it.

In order to avoid the possible instability problems that may arise due to the employment of external feedback, it is necessary to avoid using external feedback throughout the whole circuit. Also, it would be attractive for integration if a proposed implementation, avoiding the employment of external feedback, can be realized using grounded resistors. It is the purpose of this paper to present such a realization. 


\section{PROPOSED CIRCUIT}

The proposed circuit is shown in Fig. 1. Using the standard notation, the characteristics of the current conveyors can be described by $i_{x}= \pm i_{z}, i_{y}=0, v_{x}=v_{y}$ for the $\mathrm{CCII} \pm$ and $i_{x}=i_{y}= \pm i_{z}, v_{x}=v_{y}$ for the CCI \pm . Routine analysis of the circuit yields the following transfer functions

$$
\begin{aligned}
& \frac{I_{01}}{I_{i}}=\frac{1 / C^{2} R_{1} R_{2}}{s^{2}+s / C R_{\mathrm{I}}+1 / C^{2} R_{1} R_{2}} \\
& \frac{I_{02}}{I_{i}}=\frac{s^{2}}{s^{2}+s / C R_{1}+1 / C^{2} R_{1} R_{2}} \\
& \frac{I_{03}}{I_{i}}=\frac{s / C R_{1}}{s^{2}+s / C R_{1}+1 / C^{2} R_{1} R_{2}} \\
& \frac{I_{04}}{I_{i}}=\frac{s^{2}-s / C R_{1}+1 / C^{2} R_{1} R_{2}}{s^{2}+s / C R_{1}+1 / C^{2} R_{1} R_{2}} \\
& \frac{I_{05}}{I_{i}}=\frac{s^{2}+1 / C^{2} R_{1} R_{2}}{s^{2}+s / C R_{1}+1 / C^{2} R_{1} R_{2}}
\end{aligned}
$$

Equation (1) corresponds to the transfer function of a lowpass filter, equation (2) corresponds to the transfer function of a highpass filter, equation (3) corresponds to the transfer function of a bandpass filter, equation (4) corresponds to the transfer function of an allpass filter, and equation (5) corresponds to the transfer function of a notch filter.

From (1)-(5), one can see that the parameters $\omega_{0}^{2}$ and $\frac{\omega_{0}}{Q_{0}}$ of the proposed current-mode filter realizations are given by

$\omega_{0}^{2}=1 / C^{2} R_{1} R_{2}$

and

$$
\frac{\omega_{0}}{Q_{0}}=1 / C R_{1}
$$

From (6) and (7), one can see that the parameters $\omega_{0}$ and $\frac{\omega_{0}}{Q_{0}}$ can be adjusted by tuning grounded resistors. Moreover, $\omega_{0}$ can be adjusted by tuning $R_{2}$ without disturbing $\omega_{0} / Q_{0}$. 


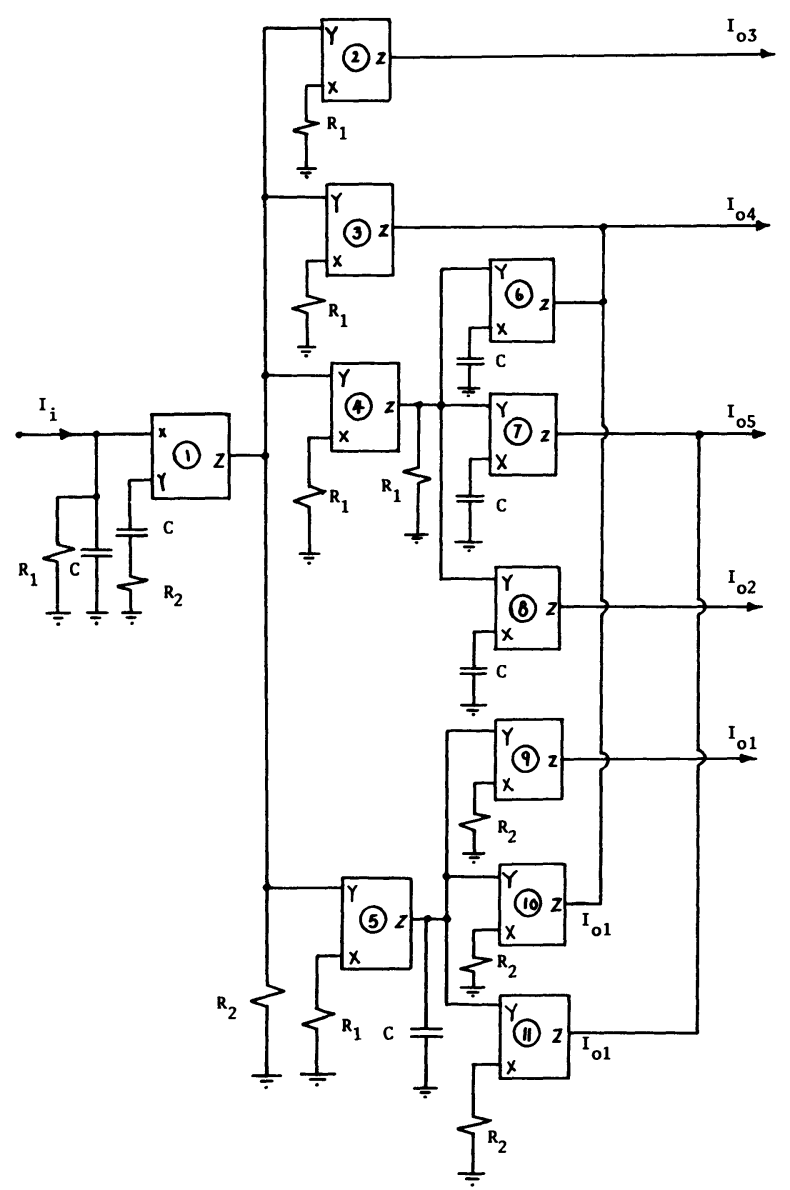

FIGURE 1 Proposed structure for realizing current-mode lowpass, highpass, bandpass, notch and allpass filters. All current conveyors are CCII + except current-conveyor \# 1 is $\mathrm{CCI}+$ and currentconveyor \# 3 is CCII - .

\section{SIMULATION RESULTS}

To verify the theoretical analysis, the proposed circuit has been simulated using PSPICE. The CCII \pm has been simulated using an operational amplifier together with current mirrors composed of transistor arrays [12] and the CCI + has been simulated using the Fabre translinear CC implementation [13]. With $R_{1}=20 \mathrm{kOhm}$, $R_{2}=100 \mathrm{Ohm}, C=5 n F$, that is, $Q_{0} \cong 14$ and $\omega_{0} \cong 23 \mathrm{kHz}$, the result obtained from the bandpass filter is shown in Fig. 2. This result is in good agreement with the theory presented. 


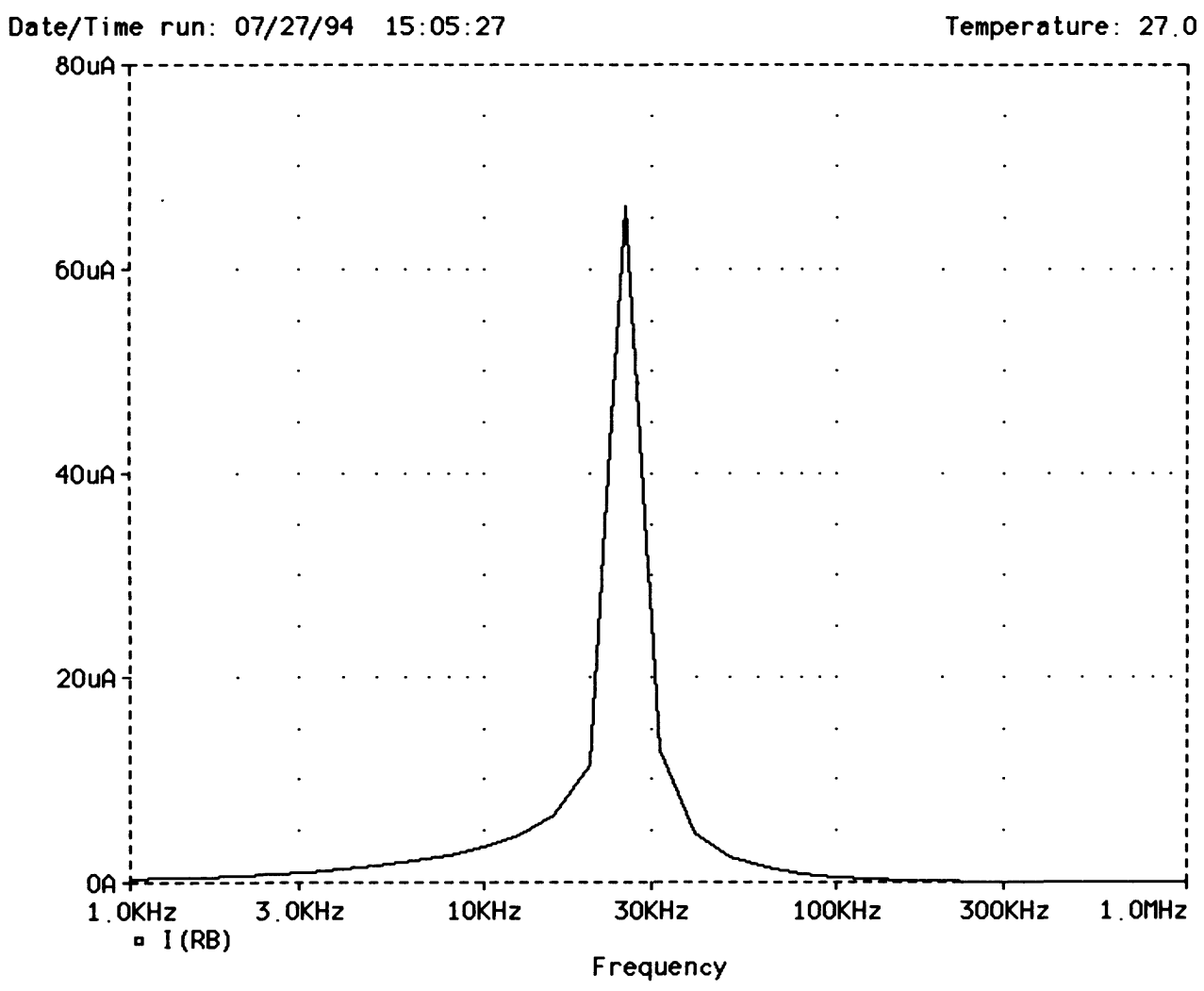

FIGURE 2 Simulated bandpass characteristic obtained from Fig. 1 with $R_{1}=20 \mathrm{kOhm}, R_{2}=$ $100 \mathrm{Ohm}, C=5 n F$. The output current is sensed by connecting a load resistance $=1 \mathrm{k} \Omega$ at the output of current conveyor \# 2 .

\section{CONCLUSION}

In this paper a novel universal current-mode active filter using current conveyors has been presented. The circuit uses eleven current conveyors and can simultaneously realize all the five standard biquadratic filter sections, the lowpass, the highpass, the bandpass, the allpass, and the notch. Values of $\omega_{0}$ can be adjusted by tuning grounded resistors without disturbing $\omega_{0} / Q_{0}$.

\section{REFERENCES}

1. G.W. Roberts and A.S. Sedra, All current-mode frequency selective circuits, Electronics Letters, Vol. 25, 1989, pp. 759-761

2. C.-M. Chang, Novel universal current-mode filter with single input and three outputs using only five current conveyors, Electronics Letters, Vol. 29, 1993, pp. 2005-2007

3. C.-M.Chang, Universal active current filter with single input and three outputs using CCIIs, Electronics Letters, Vol. 29, 1993, 1932-1933

4. C.-M. Chang and P.-C. Chen, Universal active current filter with three inputs and one output using current conveyors, International Journal of Electronics, Vol. 71, 1991, pp. 817-819 
5. C.-M. Chang, and P.-C. Chen, Realization of current-mode transfer function using second-generation current conveyors, International Journal of Electronics, Vol. 71, 1991, pp. 805-815

6. Y. Sun and J.K. Fidler, Versatile active biquad based on second-generation current conveyors, International Journal of Electronics, Vol. 76, 1994, pp. 91-98

7. C.-M. Chang, C.-C. Chien and H.-Y. Wang, Universal active current filter with three inputs using current conveyors-Part 2, International Journal of Electronics, Vol. 76, 1994, pp. 87-89

8. C.-M. Chang, Current-mode lowpass, bandpass and highpass biquads using two CCIIs, Electronics Letters, Vol. 29, 1993, pp. 2020-2021

9. C.-M. Chang, Universal active current filters using single second-generation current conveyor, Electronic Letters, Vol. 27, 1991, pp. 1614-1617

10. C.-M. Chang, C.-C. Chien and H.-Y. Wang, Universal active current filters using single secondgeneration current conveyor, Electronics Letters, Vol. 29, 1993, pp. 1159-1160

11. D.-S. Wu, Y.-S. Hwang, S.-I. Liu and Y.-P. Wu, New multifunction filter using an inverting CCII and a voltage follower, Electronics Letters, Vol. 30, 1994, pp. 551-552

12. B. Wilson, High-performance current conveyor implementation, Electronics Letters, Vol. 20, 1984, pp. 990-991

13. A. Fabre, Wideband translinear current conveyor, Electronics Letters, Vol. 20, 1984, pp. 241-242 

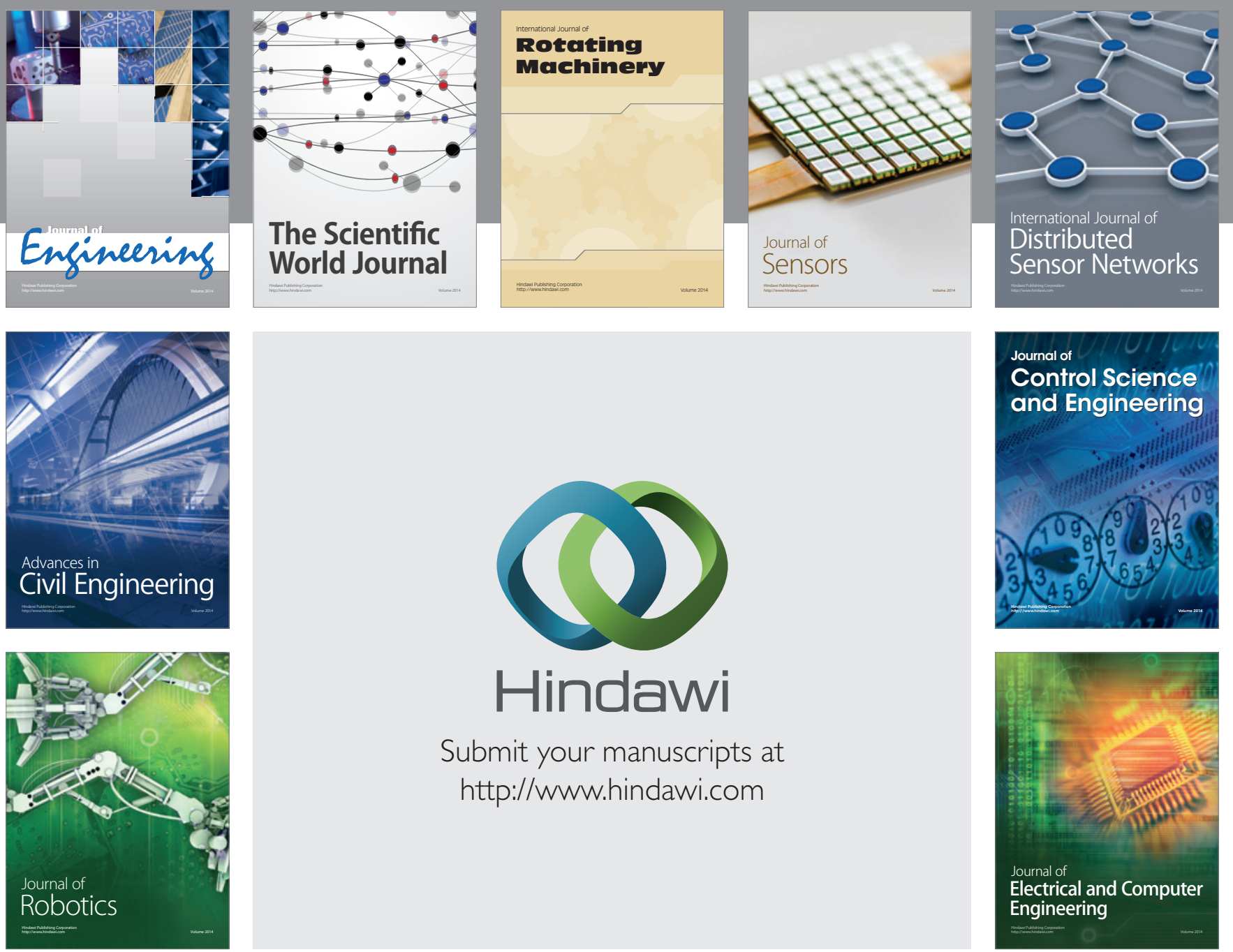

Submit your manuscripts at

http://www.hindawi.com
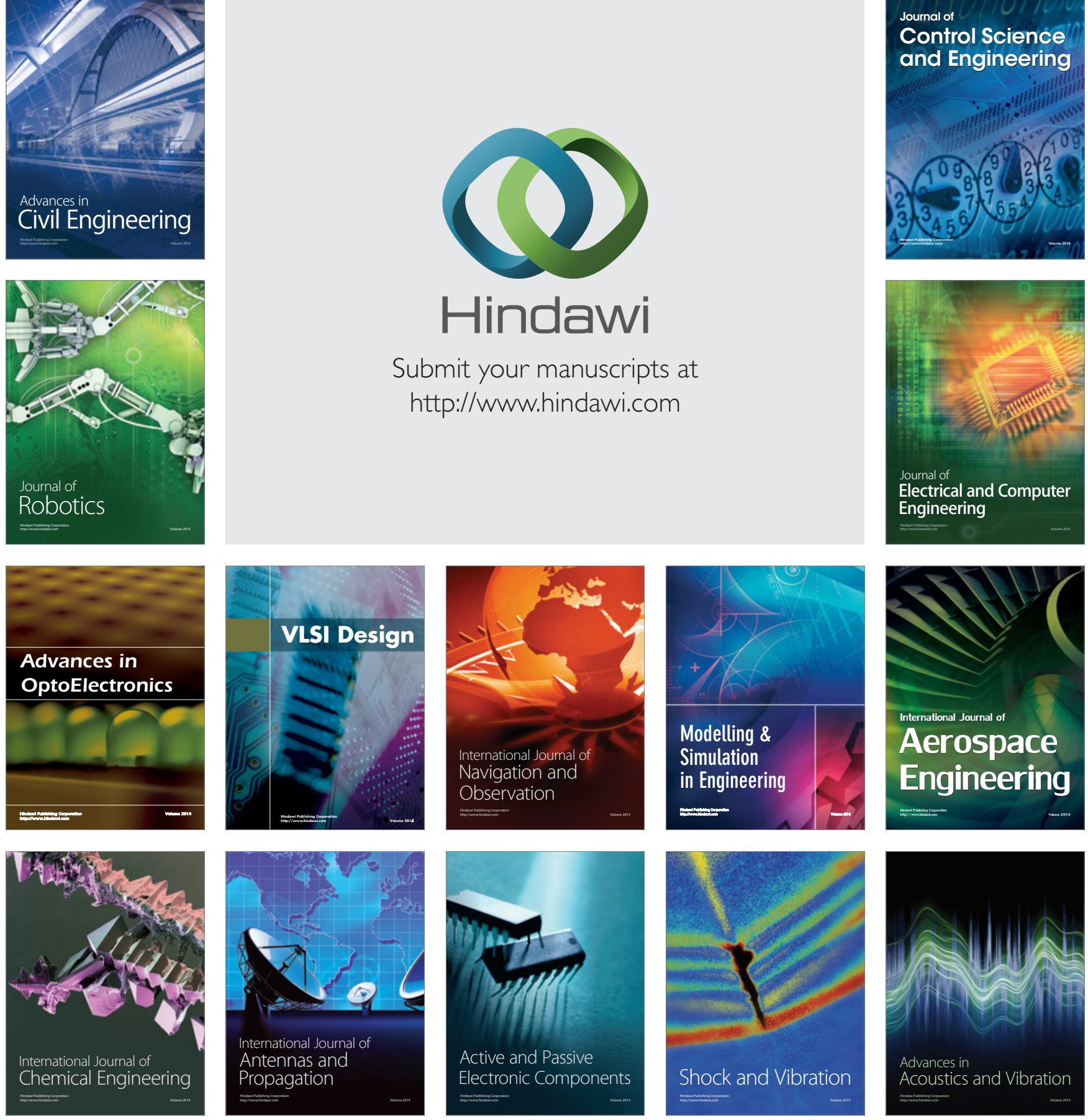